\title{
Rentabilidad de papa cisgénica versus convencional en huasahuasi
}

\author{
Profitability of cisgenic potato versus conventional in huasahuasi
}

\author{
Luis Guillén ${ }^{1}$
}

\begin{abstract}
Resumen
El objetivo de esta investigación fue obtener el impacto en la rentabilidad de la producción de papa blanca comercial cultivar Canchán por el uso de semilla cisgénica resistente a rancha en el distrito de Huasahuasi. Se manejó la hipótesis de que la semilla cisgénica incrementaría la rentabilidad y generaría incrementos en los excedentes de productores, de consumidores y de la sociedad. La unidad de análisis fueron los semilleristas de papa blanca cultivar Canchán en el distrito de Huasahuasi, provincia de Tarma, región Junín. Para la evaluación de corto plazo, se usó el método de presupuesto parcial con consideraciones de riesgo, de la rentabilidad del cultivo, comparando el cultivo con semilla convencional versus el cultivo con semilla cisgénica. Para la evaluación de largo plazo se usó el modelo de excedentes, obteniéndose el impacto sobre los excedentes del consumidor, del productor y de la sociedad. En cuanto a la rentabilidad, se obtuvo para el cultivo convencional una media de S/. 15.829,08 por hectárea, un máximo de S/. 52.832,83 y un mínimo de S/. $-5.837,41$, con valores positivos en el $97 \%$ de los escenarios posibles. Para el cultivo cisgénico se obtuvo una media de S/. 21.031,88 por hectárea, con un máximo de rentabilidad de S/. 69.595,22 y un mínimo de S/. -4.454,66, obteniendo valores positivos en el $99 \%$ de los escenarios. Respecto al impacto social de la semilla, mostrada mediante el cambio del excedente social, el incremento llega a US\$ 343 millones (sumando los excedentes de productores y consumidores) es decir, del orden de unos US\$ 20 millones anuales (mínimo de US\$ -43 millones y máximo de US\$1,35 millones, con 95 $\%$ de escenarios positivos). En conclusión, la liberación de una papa cisgénica resistente a rancha, es conveniente dada su alta rentabilidad, según los resultados obtenidos en los escenarios propuestos en el @risk.
\end{abstract}

Palabras clave: cultivos transgénicos; papa; @risk; método de excedentes.

\begin{abstract}
The objective of this research was to find the effect on the profitability of the production of commercial white potato cultivar Canchán by the use of cisgenic seed resistant to blight in the district of Huasahuasi. We worked with the hypothesis that the cisgenic seed would increase the profitability and generate an increase in the surplus of producers, consumers and society. The unit of analysis was the white potato seed growers of Canchán cultivar in the Huasahuasi district, province of Tarma, Junín region. For short-term evaluation, we used the method of partial budget with risk considerations of crop profitability, comparing the conventional seed crop versus cisgenic seed crop. For long-term evaluation we used the surplus model, obtaining the impact on consumer surplus, producer and society. In terms of profitability, we obtained for the conventional crop an average S/. 15.829,08 per hectare, a maximum of S/. 52.832,83 and a minimum of S/. -5.837,41, with positive values in $97 \%$ of the possible scenarios. For the cisgenic crop we obtained an average of S/. 21.031,88 per hectare, with a maximum profitability of S/. 69.595,22 and a minimum of S/. -4.454, 66, obtaining positive values in 99 $\%$ of the scenarios. Regarding the social impact of the seed, shown by the change in the social surplus, the increase comes to U.S. $\$ 343$ million (adding the producer and consumer surplus) in the order of about $\$ 20$ million annually (minimum U.S. \$ 43 million and up to U.S. \$ 1,35 million, with $95 \%$ positive scenarios). In conclusion, the release of a cisgenic potato blight resistant is convenient because of its high yield according to the results of the scenarios proposed in the@ risk.
\end{abstract}

Keywords: GM crops; potatoes; @ risk; surplus method.

\section{Introducción}

En el Perú es imperativo enriquecer la discusión con evaluaciones socioeconómicas ex ante de la liberación de productos genéticamente mejorados, teniendo en cuenta las condiciones propias del caso peruano (Diez, Gómez y Varona, 2013). En esta dinámica económica e inmersa en el proceso de globalización, el Perú ha firmado tratados de libre comercio con países desarrollados con excedentes en producción agrícola, quienes, además, están a la vanguardia en el uso de la biotecnología. El uso de las alternativas tecnológicas de última generación, como las de la biotecnología, permiten elevar la productividad, haciendo más competitivas a las unidades agrícolas. Es decir, permitirían fomentar la mejora de la productividad

1 Economista docente de la Facultad de Economía y Planificación. Email: 1guillen@lamolina.edu.pe 
de la papa, cultivo de gran importancia en la dieta alimentaria peruana. La biotecnología podría incrementar la competitividad de la papa frente al trigo $u$ otros productos alimenticios, pues la hipotética liberación de semillas genéticamente modificadas, resistentes a la rancha o tizón tardío (Phytophthora infestans), y tizón temprano (Alternaria solani), reducirían las pérdidas poscosecha del producto, elevando la productividad neta de las parcelas (mejorando el bienestar de los productores) y, por ende, reducirían el empleo de agroquímicos tóxicos para su salud y la del consumidor. A nivel mundial, se han realizado descubrimientos biotecnológicos incorporando genes de resistencia a la Alternaria solani (caso de tomate en Cuba) o a la Rhizoctonia solani, (caso del tabaco en EE.UU.). En Perú, el Centro Internacional de la Papa (CIP) ha obtenido papa $B t$ resistente a la polilla (Pthorimaeia operculella), que no puede ser liberada por razones legales. En Irlanda, se está sembrando la papa Desireé, desarrollada en la Universidad de Wageningen, en los Países Bajos, transformada con el gen Rpi-vnt1.1, que confiere resistencia a Phytophthora. En cuanto al cambio climático, se evidencia la existencia de nuevas condiciones climáticas en los pisos ecológicos relativas a temperatura y humedad, entre otras variables, situación que es una amenaza directa a la biodiversidad nativa (Rojas, 2013). Asimismo, se entiende que dada la sensibilidad del cultivo de papa ante el tizón tardío, es probable que un ambiente más húmedo, y caliente al mismo tiempo, genere nuevos escenarios para los productores de papa (Giraldo et al., 2010).

El objetivo del presente documento es evaluar los impactos en la rentabilidad y en los excedentes económicos, derivados de reemplazar la semilla convencional con semilla cisgénica de papa resistente a la rancha, en el distrito de Huasahuasi. Para ello, se deberá evaluar ex ante el beneficio económico y el cambio en rentabilidad para el agricultor, derivados de la liberación del uso de semilla cisgénica resistente a la rancha, así como determinar los beneficios y cambios en los excedentes económicos, generados por la inversión gubernamental en la liberación e implementación de cultivos con semilla cisgénica resistente a la rancha en el distrito de Huasahuasi.

\section{Importancia}

En Perú, durante la campaña 2010-2011, el cultivo de papa cubrió alrededor de 310 mil hectáreas, generando aproximadamente cuatro millones de toneladas (MINAG, 2012). Por otro lado, según el MINAG, la productividad del cultivo de papa no supera las $13 \mathrm{t} /$ ha debido, principalmente, al ataque de múltiples agentes bióticos, tales como la rancha (Phytophthora infestans), el gorgojo de los andes (Premnotrypes suturicallus), la polilla (Pthorimaeia operculella), los nematodos (Globodera rostochiensis, Globodera pallida), los virus y las bacterias, que generan pérdidas poscosecha del producto y reducción en la productividad neta por parcela. En este trabajo se analiza el caso de semillas de papa cisgénica con resistencia a la rancha (Phytophtora infestans). La importancia del cultivo de la papa a nivel nacional está vinculada a la variación de 67 a 83 kg entre el 2004 y el 2011 (MINAG, 2012), lo que representa un crecimiento del 8,9\% de su consumo.

En el distrito de Huasahuasi, la rancha se convierte en un problema cuando encuentra un clima propicio (calor y humedad); en las zonas donde se siembra es capaz de destruir las cosechas en su totalidad, reduciéndolas, en promedio, de 20 a $40 \%$. Los agricultores que emplean semilla contaminada intentan enfrentar el problema con la aplicación de compuestos químicos (en Huánuco fluctúa entre 16 y 21 aplicaciones) con el consecuente alto desembolso de dinero, reduciendo la rentabilidad.

\section{Alcances del problema}

En el 2009, más de 1000 millones de personas estaban sub nutridas; además, miles de niños de corta edad fallecían cada día a causa de enfermedades. Al respecto, la FAO indica que las medidas para garantizar la oferta alimentaria deben ir de la mano de medidas inmediatas que proporcionen a la población hambrienta y necesitada oportunidades de nutrición adecuada, salud y dignidad (FAO, 2009). En cuanto a la seguridad alimentaria se estimó que el abastecimiento de alimentos debería incrementarse alrededor del $75 \%$ hasta el 2025 para poder alimentar a la población mundial proyectada (Larach, 2001).

En el Perú, la introducción de la biotecnología moderna en el sector agrícola es uno de los puntos discutidos en diversas organizaciones científicas, comerciales, públicas y de consumidores. Algunos sostienen, en base a investigaciones en los países donde se han introducido los organismos genéticamente modificados (OGM), que estos traen más beneficios que costos, tanto económicos como ligados a la sostenibilidad del medio ambiente, por la reducción de los gases de efecto invernadero. Empero, hay científicos que sostienen que no existen beneficios por las semillas genéticamente modificadas y ponen en duda su inocuidad como alimento; asimismo, arguyen posibles impactos negativos para la biodiversidad y el medio ambiente. El principal exponente científico de la oposición a la liberación de transgénicos, es Gilles - Eric Seralini, quien analizó las posibles patologías que podría ocasionar el maíz híbrido NK603 GM Roundup Ready (resistente a glifosato) y concluyó que dicho maíz es letal para las células humanas, pudiendo ocasionar malformaciones, abortos, problemas hormonales y diversos tipos de cáncer (Seralini et al., 2012). Al respecto, la European Food Safety Authority (EFSA) ha cuestionado los métodos estadísticos empleados por Seralini, señalando que, en cuanto a la morbilidad por cáncer y la mortalidad, la muestra es demasiado pequeña para afirmar los impactos negativos en la salud (EFSA, 2012). En nuestro país, el cultivo de papa no produce éxito económico para muchos productores, por los problemas de rendimiento derivados de plagas y enfermedades, que explican una productividad del cultivo inferior al de muchos países (Echevarría, 2008). En el caso de los agricultores de Huasahuasi, su baja productividad se debe precisamente a estos problemas (Diez, 2012), lo cual ha llevado a la disminución de los ingresos y beneficios que obtienen los campesinos dedicados a su producción. El tizón tardío es una de las enfermedades más destructivas a nivel mundial; a la fecha se han llevado a cabo 
innumerables estudios sobre la etiología, epidemiología y control de la enfermedad, las cuales se han multiplicado aún más desde el descubrimiento del tipo A2 en Europa en 1984 y el desarrollo de métodos bioquímicos y moleculares que posibilitaron mejorar los estudios de la genética de poblaciones del patógeno. La incidencia de Phytophthora infestans es alta a muy alta en el $42 \%$ de la superficie sembrada con papa. Además, se sabe que casi la cuarta parte de la totalidad de fungicidas comercializados son aplicados para el control de la rancha; sin embargo, la resistencia genética es uno de los componentes de su manejo integrado, por ello, también se hace uso de otras prácticas, como la elección de épocas de siembra con menor incidencia de rancha, doble aporque y cosecha adelantada.

\section{Materiales y métodos Modelos de análisis}

El objeto de estudio de la presente investigación es evaluar económicamente una hipotética semilla de papa resistente a rancha liberada en Huasahuasi, mediante el enfoque de simulación, estableciendo la relación existente entre variables de costos con el rendimiento tanto a corto (evaluación de rentabilidad) como a largo plazo (modelo de excedentes).

\section{Presupuesto parcial determinístico y probabilístico.}

Se trata de calcular el efecto de un cambio sobre los costos y la ganancia de la organización existente en la explotación; solo deben calcular los costos que cambian con la nueva manera de dirigir la explotación. Según Vásquez (1992), se usa cuando se requiere hacer un análisis de la bondad de un plan alternativo respecto al plan actual, determinando efectos en los cambios que registran los ingresos y los gastos. Se usa comúnmente para estimar la rentabilidad de efectuar cambios comparativamente pequeños en una organización existente. Los presupuestos se denominan parciales porque no necesitan que se incluyan todos los costos y retribución de la producción, sino solo aquellos que cambian entre las prácticas tradicionales de los agricultores y las nuevas alternativas de evaluación. Un presupuesto parcial, entonces, es una forma de calcular el total de los costos que varían y los beneficios netos de cada tratamiento, en un experimento en la unidad agrícola.
Asimismo, incluye los rendimientos medios de cada tratamiento, los rendimientos ajustados y el beneficio bruto de campo (basado en el precio de campo de la cosecha). También incorpora todos los costos que varían para cada tratamiento.

\section{El enfoque del excedente económico}

El concepto de excedente económico subyace a muchos de los métodos utilizados por los economistas para estimar los costos y beneficios de investigaciones agrícolas o evaluar las prioridades de tales investigaciones. Como señalan Alston, Norton y Pardey (1998), la mayoría de los métodos para evaluar los impactos de los cultivos transgénicos en el bienestar social se basan en el enfoque de los excedentes económicos. Un enfoque básico es el cálculo de los beneficios de la introducción de una nueva tecnología que pueda aumentar la productividad en un $\mathrm{k}$ por ciento (una reducción del costo unitario k/tonelada) o un aumento en la producción ( $\mathrm{k} /$ hectárea), expresándose de la siguiente manera:

\section{Variables determinísticas y probabilísticas. Distribuciones de probabilidad}

A través del método del presupuesto parcial, se analiza la variación de costos entre las alternativas, una usando la semilla convencional de papa y la otra implementando la semilla mejorada genéticamente. Para la obtención de los valores esperados de las variables probabilísticas, se aplicará un análisis de riesgo con el software@RISK. Para la aplicación del modelo de presupuesto parcial, para el análisis de la liberación de semilla cisgénica resistente a rancha, se considera un aumento de hasta $70 \%$ en el costo de la nueva semilla resistente a la rancha, en relación con la semilla existente.

\section{La aplicacióndel@risk}

El uso de esta herramienta permite un análisis más completo del riesgo involucrado, al mismo tiempo permite superar algunas limitantes del método tradicional, cuando se prescinde de esta herramienta. En nuestro caso, usaremos la distribución uniforme y la distribución triangular, pero, además, se definirán adecuadamente las interdependencias del comportamiento esperado de dichas variables.

Tabla 1. Características de la metodología para el análisis ex ante

\begin{tabular}{llll}
\hline \multicolumn{1}{c}{ Ámbito } & Universo y muestra & Fuentes de información & $\begin{array}{c}\text { Adaptación de } \\
\text { metodología }\end{array}$ \\
\hline & $\begin{array}{l}\text { Universo: } 50 \text { semilleristas de } \\
\text { papa Canchán registrados en }\end{array}$ & Evaluación de corto \\
plazo
\end{tabular}




\section{Las variables a analizar}

Variables de entrada. Se usa la estructura del análisis de precios unitarios para el cultivo de la papa. A tener en consideración, en primer lugar, que los datos determinísticos están dados por información secundaria y primaria. Mientras que para las variables probabilísticas se considera el cálculo de los valores esperados (VE) de las siguientes variables: precio de los pesticidas, precio de los fungicidas, precio de la semilla convencional, producción en $\mathrm{t} / \mathrm{ha}$, precio en chacra en $\mathrm{S} / \mathrm{kg}$, precio semilla OGM, producción en $\mathrm{t} / \mathrm{ha}$, precio de los fungicidas, costos de investigación, costos de transferencia.

Variables de salida. Ratio B/C cultivo con OGM. Verifica la variación al incrementar el gasto en la aplicación de una nueva semilla en el cultivo de papa. Comprende cambio en el excedente social, cambio en el excedente productor, cambio en el excedente consumidor, VAN BN / Beneficios Netos. Muestra cuál es el resultado de los beneficios y su comparación para cada una de las alternativas analizadas, es decir, con tasas de descuento al $9 \%$ y $20 \%$.

\section{Resultados y discusión}

Para el análisis ex ante de los impactos socioeconómicos de la liberación de semilla genéticamente modificada de papa, resistente a rancha, se analizó el distrito de Huasahuasi, considerado centro semillerista de papa blanca comercial, mejorada convencionalmente, que genera semilla para los sembríos de papa en la costa y en la sierra. Con la información obtenida en encuestas a 10 semilleristas en el periodo 2011, se aplicó la metodología seguida por Falck y Zepeda $(2003,2006)$ y adaptada por Varona $(2011,2012)$ que implica un análisis de corto plazo con el modelo de presupuesto parcial en @RISK. Para el valor esperado de las variables costo total, pesticidas, fungicidas, semilla, producción y precio, se ha tenido en consideración una distribución de tipo triangular, teniendo en cuenta que los datos de las encuestas nos proporcionan el promedio, el mínimo, el máximo y la moda. Es decir, estamos en capacidad de obtener resultados válidos como inputs para el análisis del presupuesto parcial.

\section{Análisis de los costos de producción}

Para el presente análisis de costos de producción se han tomado en cuenta los datos provenientes de las encuestas

Tabla 2. Resultado de la caracterización de los costos de producción. Según encuestas aplicadas a los productores

\begin{tabular}{|c|c|c|c|c|c|c|c|c|}
\hline Entrevistado & $\begin{array}{c}\text { Costo } \\
\text { total }\end{array}$ & Pesticidas & Fungicidas & Semilla & $\begin{array}{c}\text { Producción } \\
\text { t/ha }\end{array}$ & $\begin{array}{c}\text { Precio } \\
\text { S/kg }\end{array}$ & Ingresos & $\begin{array}{c}\text { Rentabilidad } \\
\text { bruta/ha }\end{array}$ \\
\hline $\begin{array}{l}\text { Jesús Echevarría } \\
\text { Campos }\end{array}$ & 9.000 & 1.000 & 1.000 & 2.500 & 20 & 0,70 & 14.000 & 3.680 \\
\hline $\begin{array}{l}\text { Hugo Arzapalo } \\
\text { Chagua }\end{array}$ & 9.000 & & & & 16 & 0,50 & 8.000 & -2.980 \\
\hline Raúl Yantas Pérez & 17.500 & 700 & 500 & 6.500 & 20 & 0,85 & 17.000 & -3.580 \\
\hline $\begin{array}{l}\text { Edward Galarza } \\
\text { Casaño }\end{array}$ & 12.000 & 800 & 800 & 1.250 & 18 & 0,50 & 9.000 & -5.090 \\
\hline $\begin{array}{l}\text { Freddy Capcha } \\
\text { Córdova }\end{array}$ & 9.000 & 600 & 600 & 1.300 & 18 & 0,50 & 9.000 & -1.320 \\
\hline Edgo Pérez Capcha & 15.000 & 600 & 500 & 4.000 & 30 & 0,70 & 21.000 & 3.140 \\
\hline $\begin{array}{l}\text { José Javier García } \\
\text { Pando }\end{array}$ & 15.000 & 1.500 & 1.500 & 6.500 & 30 & 2,00 & 60.000 & 42.360 \\
\hline $\begin{array}{l}\text { Teodosio } \\
\text { Echevarría Campos }\end{array}$ & 17.000 & 800 & 800 & 7.000 & 35 & 0,80 & 28.000 & 7.920 \\
\hline $\begin{array}{l}\text { Hugo Palacios } \\
\text { Blancas }\end{array}$ & 15.000 & 1.000 & 1.000 & 6.500 & 35 & 0,70 & 24.500 & 6.970 \\
\hline $\begin{array}{l}\text { Carlos Galarza } \\
\text { Muñoz }\end{array}$ & 15.000 & 1.000 & 1.000 & 6.500 & 35 & 0,70 & 24.500 & 6.860 \\
\hline Promedio & 13.350 & 800 & 770 & 4.205 & 26 & 0,80 & & \\
\hline Mínimo & 9.000 & 600 & 500 & 1.250 & 16 & 0,50 & & \\
\hline Moda & & $1.000,00$ & $1.000,00$ & $6.500,00$ & 35 & 0,70 & & \\
\hline Máximo & 17.500 & 1.500 & 1.500 & 7.000 & 35 & 2 & 60.000 & \\
\hline \multirow[t]{3}{*}{$\begin{array}{l}\text { Desviación } \\
\text { Estándar }\end{array}$} & 3.334 & 386 & 403 & 2.722 & 8 & 0,44 & & \\
\hline & & $48 \%$ & $52 \%$ & $65 \%$ & $31 \%$ & $56 \%$ & & \\
\hline & $\begin{array}{l}\text { Valor } \\
\text { Esperado }\end{array}$ & $1.033,33$ & $1.000,00$ & $4.916,67$ & 28,67 & 1,07 & & \\
\hline
\end{tabular}


aplicadas a los productores de papa blanca en Huasahuasi y se han establecido las siguientes variables: el precio de la semilla, los costos de los plaguicidas y los fungicidas, el precio de la mano de obra, los costos propios de la fertilización del campo y el precio de la mecanización de la actividad. Se realizó el proceso input con distribución triangular, en@RISK, para las variables de pesticidas, fungicidas, semilla, producción y precio. Es importante tomar en cuenta que para el cálculo de los costos del cultivo cisgénico, se procedió a recalcular el precio de la semilla, los costos de los fungicidas y la producción, teniendo en cuenta la opinión de los especialistas, quienes indicaron los posibles cambios en estas variables ante la introducción de una semilla cisgénica. Para las rentabilidades, se obtuvo resultados tanto para el cultivo convencional, como para el cultivo con la liberación de la semilla cisgénica. En ambos casos, se aplicó iteraciones en @RISK, con la finalidad de simular escenarios posibles, obteniéndose que las distribuciones, en el caso del cultivo con semilla cisgénica, tienen un sesgo positivo en su mayoría.

Las opiniones de los especialistas tienen naturalmente una distribución uniforme (1 sola ocurrencia para cada valor), por ello se toman los valores máximo y mínimo para obtener el esperado, en @RISK, para cada una de las variables antes mencionadas.

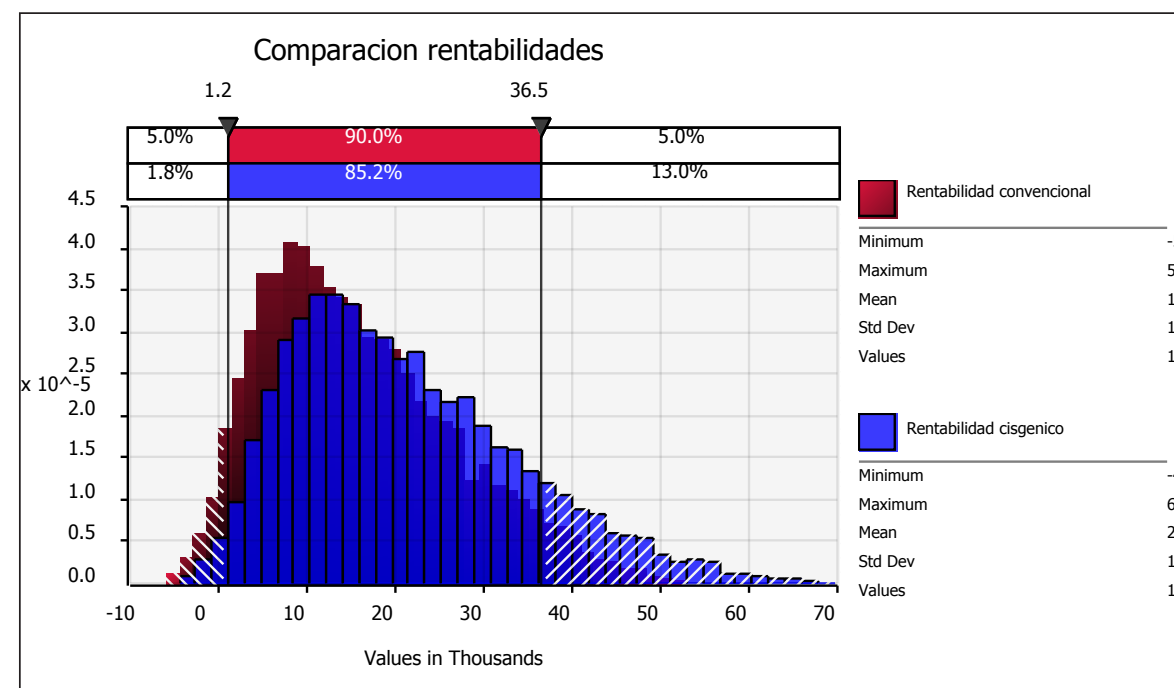

Figura 1. Comparación de las rentabilidades, por uso de semilla convencional versus cisgénica

Elaboración propia en base a uso de software@RISK

Tabla 3. Comparación de los costos de cultivo convencional y cultivo cisgénico

\begin{tabular}{|c|c|c|c|c|c|}
\hline \multicolumn{2}{|c|}{ Cultivo CONVENCIONAL } & \multicolumn{2}{|c|}{ Cultivo CISGÉNICO } & \multirow[b]{2}{*}{$\begin{array}{l}\text { Variación } \\
\text { porcentual }\end{array}$} & \multirow[b]{2}{*}{ Tipo de variable } \\
\hline Concepto & $\begin{array}{l}\text { Precio Unitario } \\
\text { (en nuevos soles) }\end{array}$ & Concepto & $\begin{array}{l}\text { Precio Unitario } \\
\text { (en nuevos soles) }\end{array}$ & & \\
\hline Semilla & $4.916,67$ & Semilla & $5.162,50$ & & Costo probabilístico \\
\hline Plaguicidas & $1.033,33$ & Plaguicidas & $1.033,33$ & & Costo probabilístico \\
\hline Fungicidas & $1.000,00$ & Fungicidas & 150,00 & & Costo probabilístico \\
\hline Mano de obra & $3.175,31$ & Mano de obra & $3.175,31$ & & Costo determinístico \\
\hline Fertilización & $4.031,80$ & Fertilización & $4.031,80$ & & Costo determinístico \\
\hline Mecanización & 609,30 & Mecanización & 609,30 & & Costo determinístico \\
\hline Costo operativo total & $14.766,41$ & Costo operativo total & $14.162,24$ & $-4,09 \%$ & \\
\hline Producción & $28.666,67$ & Producción & $32.966,67$ & $15,00 \%$ & $\begin{array}{l}\text { Rendimiento } \\
\text { probabilístico }\end{array}$ \\
\hline Precio de papa & 1,07 & Precio de papa & 1,07 & $0,00 \%$ & Precio probabilístico \\
\hline Ingresos & $30.577,78$ & Ingresos & $35.164,44$ & $15,00 \%$ & \\
\hline Rentabilidad & $15.811,37$ & Rentabilidad & $21.002,20$ & $32,83 \%$ & \\
\hline
\end{tabular}

Elaboración propia en base a encuestas realizada y resultados obtenidos en @ RISK. 
Tabla 4. Comparación de los costos de cultivo convencional y cultivo cisgénico

\begin{tabular}{lrrr}
\hline & Precio Semilla & Producción & \multicolumn{2}{c}{ Fungicidas } \\
\hline Mínimo & 0,00 & 0,00 & 0,7 \\
Máximo & 0,10 & 0,30 & 1 \\
VE & 0,05 & 0,15 & 0,85 \\
\hline
\end{tabular}

Elaboración propia en base a encuestas realizadas a especialista y resultados obtenidos en @RISK.

Tabla 5. Síntesis de criterios empleados para la evaluación - costos de producción

\begin{tabular}{|c|c|c|c|}
\hline \multicolumn{4}{|c|}{$\begin{array}{l}\text { Variación de los costos } \\
\text { Adopción de semilla cisgénica }\end{array}$} \\
\hline Variable & $\begin{array}{l}\text { Convencional } \\
\text { (en US\$) }\end{array}$ & $\begin{array}{c}\text { Cisgénica } \\
\text { (en US\$) }\end{array}$ & Factor de variación \\
\hline Semilla & $1.891,03$ & $1.985,33$ & $\begin{array}{l}+5 \% \text { (entre un mínimo de } 0 \% \text { y un máximo de } 10 \% \text {. Según } \\
\text { Fernández, E. y Ghislain, M. (CIP, GIAR), en comunicación personal, } \\
\text { señalaron que el costo no será mayor } 10 \% \text {, dadas las características } \\
\text { socioeconómicas del cultivo. Además, se considera la posibilidad que } \\
\text { el INIA lo venda al mismo precio de la convencional o, como máximo, } \\
\text { a un } 10 \% \text { más para cubrir costos). }\end{array}$ \\
\hline Fungicida & 384,62 & 57,69 & $\begin{array}{l}-85 \% \text { (entre un mínimo de } 70 \% \text {, según algunos oponentes a los } \\
\text { transgénicos y un máximo de } 100 \% \text { según expertos que consideran } \\
\text { que se anularía o minimizaría el uso de fungicidas). } \\
\text { La reducción en los costos que varían está entre el } 40 \text { y } 50 \% \text { según } \\
\text { la experiencia con control químico (Fernández-Northcote et al., 1999; } \\
\text { Navia y Fernández-Northcote, } 2000 \text { y Navia et al., 2001). }\end{array}$ \\
\hline
\end{tabular}

\begin{abstract}
Nota: Las respuestas de falta de mercado están asociadas con el desplazamiento de estas variedades por otras que son más sabrosas para el consumidor o de menor precio o se derivan de la mayor productividad de las otras variedades, más resistentes a las plagas. La degeneración está asociada al efecto de los virus.
\end{abstract}

Fuente: Elaboración propia en base a resultados obtenidos en @RISK.

\section{ANALISIS DE LOS RENDIMIENTOS Y LA PRODUCTIVIDAD}

\section{Evaluación del beneficio/costo.}

En cuanto a la relación beneficio/costo $(\mathrm{B} / \mathrm{C})$, se ha tomado en cuenta el cambio en el precio de la semilla, considerando la convencional versus la cisgénica y tomando en cuenta un cambio porcentual del $5 \%$. Además, se considera para la evaluación del ratio, en la variación de los beneficios (ingreso neto), dado los cambios en los costos de producción y los ingresos netos. El cociente responde a una variación marginal, donde se evalúa cambio del precio de la semilla ante el cambio en los ingresos netos.

Luego se identificaron las dimensiones de los cambios en costos y rendimientos que se habían obtenido a partir de la encuesta y se aplicaron los valores de la elasticidad en el precio de la oferta y de la demanda (MINAG, 2010), el precio de la papa (MINAG, 2012), la tasa de adopción según Rogers (Robinson, 2009) y la probabilidad de éxito determinada para las innovaciones en agricultura (Varona, 2012). El siguiente paso fue aplicar el modelo de

Tabla 6. Síntesis de criterios empleados para la evaluación - variación en los rendimientos y la productividad

\begin{tabular}{|c|c|c|}
\hline \multicolumn{3}{|r|}{$\begin{array}{c}\text { Variación en los rendimientos y la productividad } \\
\text { Adopción de semilla cisgénica }\end{array}$} \\
\hline $\begin{array}{c}\text { Convencional } \\
\text { (en kg/ha) }\end{array}$ & $\begin{array}{l}\text { Cisgénica } \\
\text { (en kg/ha) }\end{array}$ & Factor de variación \\
\hline $28.666,67$ & $32.966,42$ & $\begin{array}{l}\text { +15\% (entre un mínimo de } 0 \text {, según algunos oponentes a los transgénicos, y } \\
\text { un máximo de } 30 \% \text { según la evidencia empírica señalada por Aboites y Félix, } \\
\text { 2011). No se está considerando que el incremento en los rendimientos puede } \\
\text { fluctuar entre } 20 \text { y } 200 \% \text { (Navia et al., } 2001 \text { y Thiele et al., 1998) según la } \\
\text { experiencia con control químico. }\end{array}$ \\
\hline
\end{tabular}

Nota: Las respuestas de falta de mercado están asociadas con el desplazamiento de estas variedades por otras que son más sabrosas para el consumidor o de menor precio o se derivan de la mayor productividad de las otras variedades, más resistentes a las plagas. La degeneración está asociada al efecto de los virus.

Fuente: Elaboración propia en base a resultados obtenidos en @RISK. 
Tabla 7. Comparación resultados cultivo convencional versus cultivo con semilla cisgénica

\begin{tabular}{|c|c|c|c|c|}
\hline Concepto & $\begin{array}{c}\text { Cultivo } \\
\text { convencional }\end{array}$ & $\begin{array}{l}\text { Cultivo } \\
\text { cisgénico }\end{array}$ & Diferencia & $\begin{array}{c}\text { Cambio } \\
\%\end{array}$ \\
\hline Rendimiento (kg/ha) & $28.666,67$ & $32.966,67$ & $4.300,00$ & 15,00 \\
\hline Semilla & $1.891,03$ & $1.985,58$ & 94,55 & 5,00 \\
\hline Precio $(\$ / k g)$ & 0,41 & 0,41 & - & 0,00 \\
\hline Ingreso bruto $(\$ /$ ha $)$ & $11.760,68$ & $13.524,79$ & $1.764,10$ & 15,00 \\
\hline Costos de producción $(\$ /$ ha $)$ & $5.679,39$ & $5.447,02$ & $(232,37)$ & $-4,09$ \\
\hline Ingreso neto(\$/ha) & $6.081,30$ & $8.077,77$ & $1.996,47$ & 32,83 \\
\hline Superficie (ha) & & & 3.576 & \\
\hline Tasa de descuento $(\%)$ & & & 10 & \\
\hline Probabilidad éxito & & & 0.85 & \\
\hline Tasa máxima de adopción & & & 0,80 & \\
\hline Tipo de cambio & & & 2,60 & \\
\hline Variación costos de producción & & & 232,37 & \\
\hline Variación ingresos netos & & & $1.996,47$ & \\
\hline Variación beneficios (ingreso neto) & & & $2.228,85$ & \\
\hline Variación costos semillas & & & 94,55 & \\
\hline Ratio B/C (marginal) & & & & 23,57 \\
\hline
\end{tabular}

Fuente: Elaboración propia en base a resultados obtenidos en @RISK.

Tabla 8. Determinación VAN, Excedente Social, Excedente Productor, Excedente Consumidor, VAN (9 \% y 20 \%)

\begin{tabular}{|c|c|c|c|c|c|c|c|}
\hline Año & $\begin{array}{c}\text { Cambio } \\
\text { excedente } \\
\text { social }\end{array}$ & $\begin{array}{c}\text { Cambio } \\
\text { excedente } \\
\text { productor }\end{array}$ & $\begin{array}{c}\text { Cambio } \\
\text { excedente } \\
\text { consumidor }\end{array}$ & $\underset{\text { EC y EP }}{\text { Suma }}$ & $\begin{array}{c}\text { Costos } \\
\text { investigación }\end{array}$ & $\begin{array}{c}\text { Costos } \\
\text { Transferencia }\end{array}$ & $\begin{array}{l}\text { Beneficios } \\
\text { netos }\end{array}$ \\
\hline 2013 & & & & & $5.325 .000,00$ & & $(5.325 .000,00)$ \\
\hline 2014 & $612.654,18$ & $509.206,02$ & $103.448,17$ & $612.654,18$ & & $100.000,00$ & $512.654,18$ \\
\hline 2015 & $3.947 .326,34$ & $3.280 .810,58$ & $666.515,76$ & $3.947 .326,34$ & & $100.000,00$ & $3.847 .326,34$ \\
\hline 2016 & $12.542 .696,95$ & $10.424 .831,73$ & $2.117 .865,22$ & $12.542 .696,95$ & & $100.000,00$ & $12.442 .696,95$ \\
\hline 2017 & $20.360 .976,96$ & $16.922 .975,93$ & $3.438 .001,03$ & $20.360 .976,96$ & & & $20.360 .976,96$ \\
\hline 2018 & $20.360 .976,96$ & $16.922 .975,93$ & $3.438 .001,03$ & $20.360 .976,96$ & & & $20.360 .976,96$ \\
\hline 2019 & $20.360 .976,96$ & $16.922 .975,93$ & $3.438 .001,03$ & $20.360 .976,96$ & & & $20.360 .976,96$ \\
\hline 2020 & $20.360 .976,96$ & $16.922 .975,93$ & $3.438 .001,03$ & $20.360 .976,96$ & & & $20.360 .976,96$ \\
\hline 2021 & $20.360 .976,96$ & $16.922 .975,93$ & $3.438 .001,03$ & $20.360 .976,96$ & & & $20.360 .976,96$ \\
\hline 2022 & $20.360 .976,96$ & $16.922 .975,93$ & $3.438 .001,03$ & $20.360 .976,96$ & & & $20.360 .976,96$ \\
\hline 2023 & $20.360 .976,96$ & $16.922 .975,93$ & $3.438 .001,03$ & $20.360 .976,96$ & & & $20.360 .976,96$ \\
\hline 2024 & $20.360 .976,96$ & $16.922 .975,93$ & $3.438 .001,03$ & $20.360 .976,96$ & & & $20.360 .976,96$ \\
\hline 2025 & $20.360 .976,96$ & $16.922 .975,93$ & $3.438 .001,03$ & $20.360 .976,96$ & & & $20.360 .976,96$ \\
\hline 2026 & $20.360 .97,96$ & $16.922 .975,93$ & $3.438 .001,03$ & $20.360 .976,96$ & & & $20.360 .976,96$ \\
\hline 2027 & $20.360 .976,96$ & $16.922 .975,93$ & $3.438 .001,03$ & $20.360 .976,96$ & & & $20.360 .976,96$ \\
\hline 2028 & $20.360 .976,96$ & $16.922 .975,93$ & $3.438 .001,03$ & $20360.976,96$ & & & $20.360 .976,96$ \\
\hline 2029 & $20.360 .976,96$ & $16.922 .975,93$ & $3.438 .001,03$ & $20.360 .976,96$ & & & $20.360 .976,96$ \\
\hline 2027 & $20.360 .976,96$ & $16.922 .975,93$ & $3.438,001,03$ & $20.360 .976,96$ & & & $20.360 .976,96$ \\
\hline 2028 & $20.360 .976,96$ & $16.922 .975,93$ & $3.438 .001,03$ & $20.360 .976,96$ & & & $20.360 .976,96$ \\
\hline \multirow[t]{4}{*}{2029} & $20.360 .976,96$ & $16.922 .975,93$ & $3.438 .001,03$ & $20.360 .976,96$ & & \multirow{4}{*}{$\begin{array}{r}\text { VAN (TSD } \\
9 \%) \\
\text { VAN (TSD } \\
20 \%) \\
\text { TIR }\end{array}$} & $20.360 .976,96$ \\
\hline & $342.878 .308,86$ & $284.982 .463,27$ & $\mathbf{5 7 . 8 9 5 . 8 4 5 , 5 9}$ & $342.878 .308,86$ & & & $149.335 .036,03$ \\
\hline & & & & & & & 71.352.884,07 \\
\hline & & & & & & & 99,93 \\
\hline
\end{tabular}

Fuente: Elaboración propia en base a resultados obtenidos en @ RISK.

\begin{tabular}{lr}
\hline \multicolumn{1}{c}{ Opiniones } & \multicolumn{1}{c}{ Costo investigación } \\
\hline Enrique Fernández & $650.000,00$ \\
Marc Ghislain & $2.400 .000,00$ \\
Salomón Pérez & $10.000 .000,00$ \\
\hline
\end{tabular}


excedentes (Alston et al., 1999), en entorno probabilístico, con el software@RISK, para evaluar la rentabilidad de la liberación de semilla cisgénica en el largo plazo. Para la determinación del VAN, se ha de mencionar que se ha tomado dos escenarios; el primero tiene en cuenta la tasa social de descuento (TSD) dispuesta por el Ministerio de Economía y Finanzas a través del Formato 10 SNIP, donde se considera que esta tasa asciende al $9 \%$; mientras que para el otro escenario, se ha tomado como tasa la indicada en el tarifario de AGROBANCO, donde se consigna una tasa activa en moneda extranjera del $20 \%$. Asimismo, se deberá precisar que las elasticidades corresponden a lo determinado en el 2010 por MINAG a través de la Oficina de Planeamiento y Presupuesto, en la Unidad de Política Sectorial.

Tabla 9. Resultado del análisis ex ante de papa GM resistente al tizón tardío - del presupuesto parcial

\begin{tabular}{l}
\hline Método - Presupuesto parcial \\
\hline Beneficio/Costo $(\mathbf{B} / \mathbf{C})$ marginal 23,57 \\
Mínimo 0,40 \\
Máximo $6.352,42$ \\
El $100 \%$ de escenarios B/C resulta positivo. \\
Modificación genética evaluada \\
Resistencia a rancha sobre cultivar Canchan. \\
Variación de rendimiento \\
$+15 \%$ \\
Mínimo de $0 \%$ \\
Máximo el $30 \%$ \\
Según la evidencia presentada por Aboites et al., 2011. \\
Variación de costos (en semilla mejorada) \\
$+5 \%$, por mayor costo de la semilla mejorada \\
\hline
\end{tabular}

Fuente: Elaboración propia en base a resultados obtenidos en @RISK.

Tabla 10. Resultado del análisis ex ante de papa GM resistente al tizón tardío - del modelo de excedentes

Método $\quad$ Modelo de excedentes en@RISK

Inversión pública: Se considera un valor esperado de inversión acumulada en valor actual de 5.325 millones de dólares. Los cuales se invertirían durante el primer año en actividades de investigación. Esta cifra es resultado de las entrevistas realizadas a especialistas como Enrique Fernández (US\$ 650.000), Marc Ghislain (US\$ 2.400.000) y Salomón Pérez (US\$ 10.000.000). Se tomó en cuenta el máximo y el mínimo para la aplicación de una distribución uniforme en @ RISK. Además, se considera que se gastaría 300.000 durante los tres años por concepto de transferencia tecnológica. Se ha de tener en consideración que se está tomando como área de intervención tan solo al distrito de Huasahuasi y su actividad papera. Estos valores esperados se han calculado en base a datos obtenidos en conversaciones con el Ing. Rolando Egúsquiza, el Dr. Félix Camarena y el Dr. Enrique N. Fernández-Northcote, de la UNALM; con científicos del CIP, el Dr. Guy Hareau y el Dr. Marc Ghislain, y la economista del CIAT, la Dra. Carolina Gonzales.

Incremento del excedente social: El valor del incremento en excedentes para toda la sociedad es de aproximadamente 343 millones de dólares americanos. Mínimo -43 millones. Máximo 1,350 millones.

Los valores son positivos en más del $95 \%$ de los escenarios posibles.

Valor Actual Neto (VAN) de la inversión en mejora de la semilla cisgénica: Se ha realizado el análisis para dos escenarios, uno teniendo en consideración una Tasa Social de Descuento de 9 \% y otro con una Tasa Social de Descuento de $20 \%$. Este último, para simular un escenario donde la intervención gubernamental es nula, determinando un incremento considerable en la Tasa Social de Descuento.

Con Tasa Social de Descuento $9 \%$

Valor Esperado obtenido como output de @RISK, es de aproximadamente 149 millones de dólares americanos: Mínimo -13 millones. Máximo 571 millones.

Los valores son positivos en el $95 \%$ de los escenarios posibles.

Con Tasa Social de Descuento $20 \%$

Valor Esperado obtenido como output de @RISK, es de aproximadamente 71 millones de dólares americanos: Mínimo -4 millones. Máximo 265 millones.

Los valores son positivos en el $98 \%$ de los escenarios posibles.

Fuente: Elaboración propia en base a resultados obtenidos en @ RISK. 


\section{Conclusiones}

El modelo de presupuesto parcial aplicado en @ RISK a los flujos en dólares arroja un B/C de 23,57 (valor mínimo de $-0,40$ y máximo de $6.352,42$ ). Siendo positivo en más de $95 \%$ de los casos probables. En cuanto a los resultados de la comparación de rentabilidad, de los datos procesados en @RISK, se obtuvo para el cultivo convencional un máximo de S/. 52.832,83 por hectárea versus un mínimo de $\mathrm{S} /-5.837,41$ por hectárea, el rango de valores positivos es de $97 \%$. Para el caso del cultivo cisgénico se obtuvo como máximo una rentabilidad de $\mathrm{S} /$. 69.595,22 por hectárea y un mínimo de S/ -4.454,66 por hectárea, siendo el rango de los valores positivos del $99 \%$. La evaluación de largo plazo en condiciones de riesgo con el modelo de excedentes en Excel de Alston et al. (1995), evaluado en entorno probabilístico con el software@RISK, arroja un VAN del incremento en excedentes de $9 \%$, para el caso de Tasa Social de Descuento, de US\$ 149 millones (mínimo US\$ -13 millones y máximo de US\$ 571 millones, con $95 \%$ de escenarios positivos). Mientras que cuando la Tasa Social de Descuento es de $20 \%$, el resultado es de US\$ 71 millones (mínimo US\$ - 4 millones y máximo de US\$ 265 millones, con $98 \%$ de escenarios positivos). La evaluación de largo plazo de la conveniencia de introducir la innovación genética en papa blanca comercial, da como resultado un incremento de excedente del productor de US\$ 285 millones (mínimo US\$ -6,4 millones y máximo de US\$ 1,26 millones, con $95 \%$ de escenarios positivos). Para la sociedad, mostrada mediante el cambio del excedente social, el incremento llega a US\$ 343 millones (sumando los excedentes de productores y consumidores), es decir, del orden de aproximadamente US\$ 20 millones anuales (Mínimo de US\$ -43 millones y máximo de US\$ 1,35 millones, con $95 \%$ de escenarios positivos). De los resultados obtenidos, se entiende que la liberación de una papa cisgénica resistente a rancha, es conveniente dada su alta rentabilidad, según los resultados obtenidos en los escenarios propuestos en el @RISK. Además, se espera que en el caso peruano sea aún más rentable, dadas las condiciones en la cuales se trabaja a nivel del campo alto andino, considerándose que se ha elaborado el análisis en un escenario conservador. Por otro lado, se considera recomendable realizar este tipo de estudios en otros ámbitos geográficos. Además, se debe tener en cuenta para posteriores investigaciones la inclusión de las variables ambientales.

\section{Literatura citada}

Aboites, G. y Félix, G. 2011. Centroamérica: Uso de semillas genéticamente modificadas e incremento del ingreso de los agricultores. México: CEPAL. Sede Sub Regional México.

Science under scarcity. Principles and practice for agricultural research evaluation and priority setting. New York: CAB International.

Diez, R. 2012. Perú, Adaptación de métodos y herramientas para la evaluación ex-ante del impacto socio-económico de la introducción de OVM de maíz y papa en los trópicos y centros de biodiversidad en el Perú. Conferencia Regional sobre Bioseguridad. Cartagena de Indias, 2012.

Diez, R.; Gómez, R. y Varona, A. 2013. Análisis de metodologías de evaluación antes y después de cambios tecnológicos: el caso de la liberación de los organismos genéticamente modificados en Perú. Fórum Empresarial, Universidad de Puerto Rico. Puerto Rico.

Egúsquiza, B. y Apaza, W. 2005. La Rancha de Papa (Phytophthora infestans) en el Perú. Perfil de País: Estado Actual del Manejo Integrado de Tizón Tardio (MIP - Tizón) en Países Andinos.

Falck - Zepeda, J.; Cohen, J. y Komen, J. 2003. Impact assessment and agricultural biotechnology-research methodologies for developing, emerging and transition economies. In Organization for Economic Cooperation and Development (OECD) (Ed). Accessing agricultural biotechnology in emerging economies. Paris, France.

Falck Zepeda, J.; Barreto-Triana, N.; Baquero, I.; Espitia, E.; Fierro, H. And López, N. 2006. An Exploration of the Potential Benefits of Integrated Pest Management Systems and the Use of Insect Resistant Potatoes to Control the Guatemalan Tuber Moth (Tecia solanivora Povolny) in Ventaquemada, Colombia. EPT Discussion Paper 152, IFPRI.

Giraldo, D.; Juárez, H. y Pérez, W. 2010. Severidad del tizón tardio de la papa (Phytophthora infestans) en zonas agrícolas del Perú asociado con el cambio climático.

Echevarría, N. 2008. Impacto económico del uso de semilla certificada de papa (Solanum tuberosum), cultivar Canchán, distrito de Huasahuasi, provincia de Tarma, Región Junín; Campaña Agrícola 2006-2007. (Tesis de Maestría en Economía Agrícola), Universidad Nacional Agraria La Molina.

European Food Safety Authority [EFSA]. 2012. Declaration EFSA Journal 2012, 10 (11), 2986. Final review of the Séralini et al. (2012a) publication on a 2-year rodent feeding study with glyphosate formulations and GM maize NK603 as published online on 19 September 2012 in Food and Chemical Toxicology. Parma, Italia.

FAO. 2005. Repercusiones de los Cultivos Transgénicos en la Salud y el Medio Ambiente. El Estado Mundial de la Agricultura y la Alimentación 2003 - 2004. FAO.

Larach, M. 2001. Serie 10. El Comercio de los Productos Transgénicos: El Estado del Debate Internacional. Santiago de Chile: División de Integración y Comercio Internacional. CEPAL.

Ministerio de Agricultura [MINAG]. 2011. Anuario Agrícola. Lima, Perú: Gerencias/Direcciones Regionales de Agricultura - Sub Gerencia/Dirección de Estadística/ Dirección de Información Agraria.

Navia, O.; Gandarillas, A. y Fernández-Northcote, E. N. 2001. Estrategias de integración de resistencia y control químico del tizón de la papa (Phytophthora infestans): Validación con instituciones. Revista Latinoamericana de la Papa, 12: 153-168.

Robinson, L. 2009. A summary of Diffusion of Innovations. Fully revised and rewritten. Recuperado de http://www. enablingchange.com.au/Summary_Diffusion_Theory.pdf 
Seralini, G.; Clair, E.; Mesnage, R. y Steeve, G. 2012. Long term toxicity of a Roundup herbicide and a Rounduptolerant genetically modified maize. Food and Chemical Toxicology, 50: 4221-4231.

Varona, A. 2011. Análisis de Metodologías de Evaluación Ex - ante de los costos y beneficios de la liberación de Organismos Genéticamente Modificados en Perú. (Tesis para optar el título de Economista). Universidad Nacional Agraria La Molina. Perú.

Varona, A. 2012. Adaptación de Metodologías para la Evaluación Ex - ante de los costos y beneficios de la liberación de los Organismos Genéticamente Modificados: El caso de la papa en el distrito de Huasahuasi, Provincia de Tarma, Región Junín. (Tesis para optar el diploma de Magister Scientiae en Economía Agrícola), Universidad Nacional Agraria La Molina. Perú. 